\title{
PERMISSION-BASED ELECTRONIC MAIL FACTORS FROM RECIPIENT'S PERSPECTIVE
}

\author{
SAEID TORKAMAN \\ International Business School \\ Universiti Teknologi Malaysia \\ NORSHIDAH MOHAMED \\ College of Business Administration, \\ Prince Sultan University, Kingdom of Saudi Arabia
}

\begin{abstract}
The research explores permission-based electronic mail (e-mail) factors. Permission-based e-mail refers to recipients who had previously agreed to receive advertisements or messages sent via an e-mail from a company. These factors are conceptualized as recipients' intention to open, read, click and forward e-mails. The research uses the survey research approach. The target sample was 160 post-graduate students of a business school at a leading institution of higher learning in Malaysia. Data analysis for the research was performed using SPSS Version 21. The usable number of responses was, however, 145. The results shed light into permission-based e-mail factors from a recipient's perspective. A recipient who intends to open an e-mail has the intention to read it, click a link on it and forward it. Notably, this is driven by a specific combination of factors in an e-mail that is important from a recipient's perspective. Implications for theory and practice are discussed herein.
\end{abstract}

Keywords: Permission-based e-mail, internet marketing, electronic commerce, permission marketing.

\section{Introduction}

Since the emergence of the Internet as a channel to conduct business and in driving electronic commerce, electronic mail (e-mail) has become a generally acceptable promotional tool worldwide. E-mail is often used in current businesses to communicate and to market products or services electronically. Banner, link or button exchange used in e-mail for advertising purposes has emerged as a form of acceptable communication in targeting desired market segments (Chaffey, 2003; 2007). 
Users receive e-mail because they had previously agreed to receive e-mails. This is in line with the notion of permission marketing; a term coined by Godin (1999). This gives rise to permission-based e-mail. The idea of getting customers' approval to send them advertisements is not a new approach; this approach was first introduced in the context of privacy issues in direct marketing (Milne \& Gordon, 1993). Besides, this is to distinguish permission-based e-mails from unsolicited ones commonly referred to as spam. In this research, our focus is on permission-based e-mail. The key attribute in permission-based e-mail is to convey to recipients the company's understanding of their interests and fulfill their information needs (Sterne \& Priore, 2000).

E-mail is one of the most significant channels to reach more customers effectively (Huang \& Shyu, 2009). First and foremost, advertisements through e-mail are less expensive compared to other media such as direct mail or printed newsletters. Second, return on investments has been shown to be higher for marketing that uses e-mail when done properly. Next, it is instant and faster compared to mail advertisements and it is easy to keep track of customers via cookies. Besides, it can reach out to a number of respondents within a short span of time (Chaffey, 2003; 2007; Huang \& Shyu, 2009; Jolley et al., 2013). This is supported by Forrester Research (2010) who demonstrated that investments in e-mail for marketing purpose would reach $\$ 2$ billion by 2014. Moreover, the Direct Marketing Association (DMA) suggested that the return on investment from using e-mail in marketing is more than $\$ 43$ for every dollar spent. Further, more than $50 \%$ of customers made their purchases as a result of e-mail.

According to Huang and Shyu (2009), e-mail characteristics that are asynchronized and convenient in communication between Internet retailers and their customers, are used to target more respondents accurately and instantaneously. Moreover, e-mail provides chances for direct communication, and enables customer's loyalty and trust. As a result, e-mail has become increasingly popular as a mode of communication and in creating product awareness among marketers in the online environment, in comparison to other modes of advertisements (Chaffey, 2003; 2007).

The subject of e-mail used in marketing has captured the attention of both researchers and practitioners due to its significant contributions to businesses. Of particular concern, is the recipient's intention to receive e-mails. This relates to the e-mail recipient's behavior that is followed by intention. 
A successful e-mail campaign concerns purchase behavior as a response. This suggests opportunities for the investigation of e-mail factors that are associated with receipt of such an e-mail from the recipient's perspective.

\section{Problem Statement}

Prior research on e-mail used in marketing suggests that time and frequency are the key factors in an e-mail (Merisavo \& Raulas, 2004) and, entertainment and informativeness (Jamalzadeh et al., 2012). These studies are in isolation of each other. Other studies, however, are concerned with the user's characteristics that include gender, age and attitude (Grimes et al. 2007). While the latter focused on the user's individual demographic and attitudinal characteristics, it remains that other factors of an e-mail continued to be apparently omitted in subsequent studies.

\section{Research question, research objective and scope}

In fulfilling the gap, the present research sets out the following research question: What are the permission-based e-mail factors from a recipient's perspective? The research sets out to identify the permission-based e-mail factors and to investigate the validity and reliability of the factors. In this regard, the concern is to explore the recipient's behavioral intention and the characteristics of an e-mail as factors from a recipient's perspective. The research scope covers only permission-based e-mail whereby a user has allowed himself or herself to receive an e-mail via agreeing to its receipt at a website. The recipient's individual characteristics, however, are not the subject of interest in the present research.

\section{Literature Review}

The result of a survey carried out by IMT Strategies in the late 1990s shows that permission-based e-mails provides a higher response rate compared to non-permission-based e-mails. The research suggests that approximately more than half of the customers felt positive about receiving e-mails as advertisements and product awareness. The outcomes entail permission e-mail as a tool for conveying information that may be used to build a long-term relationship subject to agreement by the respondents. Accordingly, this would be 
a key interest to Internet retailers whose need is to reach potential consumers in the virtual environment. This empirical evidence, thus, forms the support for the present research on gaining permission from e-mail users. The notion of gaining permission establishes in the minds of recipients that the e-mail has relevance to them, is not a spam and thus may be worth opening for a review and consequent actions on their part.

Prior researches appear to suggest that a user's perspective (Sterne \& Priore, 2000; Kautonen et al., 2007; Broekhuizen \& Huizingh, 2009; Amin et al., 2013), e-mail characteristics (Rettie et al. 2002) and website or portal characteristics (Liao et al. 2011) influence a user's response. For instance, evidence has been found that knowledge of customers' interests and their information needs are key elements in permission-based e-mails (Sterne \& Priore, 2000). Building on this notion, this research traces other related studies that focused on e-mail characteristics that appeal to recipients.

The sources of e-mail recipients' agreeing to receive e-mail would vary. Kautonen et al. (2007) suggest that for countries in Europe such as Germany and Finland, Facebook and Twitter are sources for permission-based e-mail. However, in the United Kingdom, user's experience provides a trigger for the acceptance of permission-based e-mail and intention in participating in online marketing campaigns.

From a user's perspective, Broekhuizen \& Huizingh (2009) found four dominant factors that influence consumers to agree to permissionbased e-mail and accept online shopping promotions. These constitute time and effort saving, level of enjoyment they feel, the risk perceived when giving out private information (such as name and e-mail address) and level of promotion depth and promotion frequency of the e-mail.

Rettie et al. (2002) suggests that an e-mail's attractiveness of the subject line and the offer inside the e-mail, the recipient's opening of the e-mail and clicking on the link inside the e-mail constitute a recipient's response process. Further, it was found that the response rate of an e-mail marketing campaign is positively related to the e-mail subject line; which implies, a more attractive e-mail subject line elicits a higher response rate. Rettie et al. (2002) consequently found evidence that the response rate would increase if an e-mail's length is increased. Besides, the research found support for an increase in 
the response rate for an e-mail that includes an image in its content. In this similar research, the number of response rates to an e-mail is highly related to the incentive and the offer the e-mail provides to the recipients.

Amin et al. (2013) reported that consumer behavior toward e-mail advertisement is more positive if the e-mail is sent to them with prior permission. Besides, in their research of 220 respondents, they found that permission-based e-mail with an attractive financial offer in it, makes recipients perceive it as less intrusive. However, they did not focus on the behavior of the recipients following the receipt of the permission-based e-mail.

In another study, Teo (2005) indicated that providing personalized e-mail to customers, would create a feeling of uniqueness in them. This feeling can help to differentiate a brand from another. More recently, Huang \& Shyu (2009), found that an e-mail is not a taskoriented communication medium and providing e-mails with appropriate contents to customers can enhance service quality and customer loyalty. This is supported by Merisavo \& Raulas (2004) who found that permission-based e-mail had an impact on customers' brand loyalty.

The notion of permission-based e-mail as suggested in prior researches indicates the potential of applying website or portal characteristics to permission-based e-mail factors. For instance, Liao et al. (2011) in their research on 215 respondents found evidence for a direct and positive relationship between creativity and the state-ofart design of a web portal with user intention to get engaged with the content of the portal. This resonates with Kabadayi and Gupta (2011) who found support for a significant relationship among website content, website customization, user satisfaction and intention to revisit the website.

Past literature suggest the importance of permission-based e-mail, although it appears that gaps still exist in the characteristics of permission-based e-mail that may appeal to recipients.

Therefore, the present research, in line with the review of literature and in filling the void that still exists, develops a research model that applies the e-mail characteristics, website or portal characteristics and user's perspective of e-mail characteristics that elicit a response to the e-mail. 


\section{Theoretical Foundation, Variables, Hypotheses and Research Model}

The research adopts Chaffey's (2003; 2007) creative, relevance, incentive, timing, integration, sopy-writing, attributes and landing page (acronym: CRITICAL) e-mail factors as the theoretical foundation. CRITICAL factors were cited as success factors in permission-based e-mail (Chaffey, 2003; 2007). In addition, the present research uses intention instead of actual behavior as intention has been used to predict behavior (Fishbein \& Ajzen, 1975). Thus, the research integrates Chaffey's (2003; 2007) CRITICAL framework and Fishbein \& Ajzen's (1975) downstream research framework in developing a research model to explain a recipient's intention in the context of permission-based e-mail. Fig. 1 shows the research model.

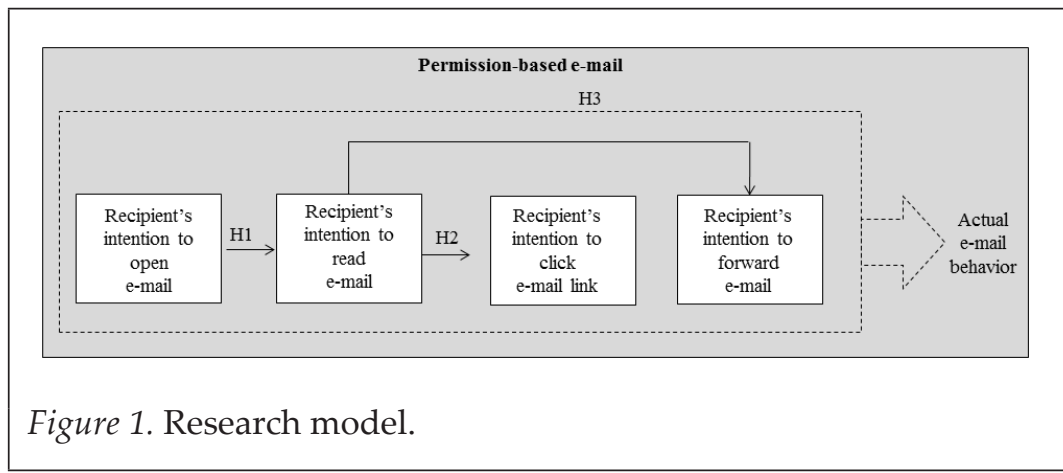

A creative e-mail connotes an attractive overall design of e-mails sent to targeted customers (Chaffey, 2003, 2007. It includes an appropriate layout, use of attractive colors and content (Chaffey, 2003, 2007; Liao et. al., (2011). According to Liao et al. (2011), a colorful design and an attractive website can increase a user's intention to go through the content of the page. Besides, the chance of a user revisiting the website with an attractive design is relatively high. Consequently, Ha \& Im (2012) found that an attractive website design (colors, font and background image) increased positive perception and satisfaction. It was concluded that a website with an attractive design would appeal to customers and increase word-of-mouth marketing.

A relevant e-mail suggests the extent that an e-mail is related to a customer's needs (Chaffey, 2003; 2007; Godin, 1999). For example, if a customer subscribes to receiving travel deals, then the e-mail should contain travel information and not any other topic to make the e-mail message attractive to the recipient. Rettie et al. (2002) found that the 
majority of users preferred to receive more relevant e-mail rather than just generalized newsletters. This is consistent with Krishnamurthy (2001).

Incentive in an e-mail is coined as an offer, promotion or discount in a permission-based e-mail campaign (Chaffey, 2003; 2007). A recipient becomes enthusiastic to find out what he will get upon opening the e-mail or clicking on the link inside the e-mail (Chaffey, 2003; 2007). This is commonly abbreviated as the WIFM (what's in it for me) factor of e-mail marketing. It has been found that a majority of research participants require an offer be made in an e-mail (Rettie et al. 2002). This is consequently supported in Martin et al. (2003) who found that increasing the perception of usefulness of an e-mail in terms of offering promotions or new products, would increase the possibility of buying from an online store. María-José Miquel-Romero \& Consolacion Adame-Sánchez (2013) found that there was a significant relationship between perceived value that a recipient acquired from an e-mail message and the association of the recipient with the sender. They also indicated that if the recipient felt that the message provided was of value to others, there would be a high chance of the recipient forwarding the message to others.

Time refers to the time of the day, week or year in which the e-mail is received (Chaffey, 2003; 2007). A recent research found that the best day of the week to send an e-mail is on Tuesday, since Tuesday is the peak day for Web traffic (Chaffey, 2013). There are fewer e-mails sent on a Friday and on a weekend as it appears that a weekend has a lower open-rate as people are less engaged during the weekend.

Integration in permission-based e-mail refers to the unification of e-mail message, design, header and subject, and the time that the message is sent that aligns with the business brand. All these aspects should be consistent with each other and with the business and the brand personality to achieve an effective permission-based e-mail campaign (Chaffey, 2003; 2007).

Copy-writing refers to the structure of the e-mail content that includes font, style and explanation of offer. It also refers to the location of the link to a Website in the e-mail message (Chaffey, 2003; 2007). Chaffey $(2003,2007)$ suggested that copy-writing would address excitement in recipients, capturing their attention and convincing them. Copywriting would indicate a natural e-mail such that the recipient would not feel that a machine wrote it. The salutation used to address the 
e-mail recipient is covered within copy-writing. Copy-writing an e-mail results in a concise e-mail. A long e-mail is not effective even if it is relevant and entertaining since readers are not willing to go through it word-by-word. The notion is consistent with the finding of Huang and Shyu (2009) that copy-writing is related to a recipient's behavior and attention. The use of a proper language in an e-mail would influence a customer to feel more comfortable.

E-mail attributes refer to e-mail characteristics that include; subject line, from address, to address, date or time of receipt and the technical format of the e-mail (HTML, mobile compatible etc.). Chaffey (2003; 2007) emphasizes that an e-mail header should contain the key message. It is the first thing that appears in the recipient's inbox; therefore, it has a significant effect on the recipient's intention to open, read, click on the link and forward the e-mail. This factor is important because a mistake made in the attributes could result in the e-mail being sent to a wrong address or to be classified as spam (Chaffey, 2003; 2007). This importance is supported in Karson and Fisher (2005) who found that website attributes have direct relationship with user's intention to return to a Website.

Landing page is the Web page that is displayed to the e-mail recipient when a link in the e-mail is clicked. Landing page is a page that provides more explanation about an offer or a form asking the recipient to enter information. Designing a landing page in a way that it is easy and understandable to the user is important for an effective e-mail campaign (Chaffey, 2003; 2007). The design of a landing page is an important factor in attracting customers to engage with the e-mail. Law and Bai (2007) found that the quality of landing pages is significantly related to user's satisfaction. Moreover, according to Liao et al. (2011), website color and design are significantly related to user's perceived web page attractiveness.

In consideration of all the permission-based e-mail factors discussed above, it is posited that:

H1: Recipient who intends to open an e-mail intends to read the e-mail.

H2: Recipient who intends to read an e-mail intends to click a link in the e-mail.

H3: Recipient who intends to read an e-mail intends to forward the e-mail to others. 


\section{Methodology}

This section discusses the methodology of the research. It covers theoretical foundation, variables, hypotheses, research model, research approach, research instrument, population and sampling.

\section{Research Approach and Research Instrument}

A cross-sectional survey research was used to answer the research question. An instrument was developed by adapting items in prior researches (Rettie et al., 2002; Chaffey, 2003; 2007; Liao et al., 2011) to ensure content validity. The questionnaire required respondents to provide demographic information, answer the number of times they checked e-mail in a day besides indicating the responses on a scale of 1 (strongly disagree) through 5 (strongly agree). A pilot test was carried out to ensure the reliability of the instrument prior to the final data collection. All items were found reliable in the pilot test.

\section{Population and Sampling}

The targeted population for this research were active Master students and PhD candidates of a business school at a leading institution of higher learning in Malaysia. The estimated population was 500 that included both active full-time and part-time fee-paying students; the estimation was made following the unavailability of a list that defines non-enrollment of students in courses during the particular semester that the data was collected. Convenience sampling was used in this research to gather data. Convenience sampling means collecting data from respondents who are readily available (Sekaran, 2006). In prior studies, convenience sampling was used in online shopping contexts (Mohamed et al., 2014; Ramayah \& Ignatius, 2005), online channels (Lu et al., 2011) and virtual banking (Liao et al., 1999). These four researches provide a basis for convenience sampling in researches on online environment and therefore lend support to the permissionbased e-mail context. In the present research, the target sample size was 160 .

\section{Findings}

Data analysis for the research was performed using SPSS Version 21. A total number of 160 questionnaires were distributed. The number of usable responses was 145. A survey questionnaire that had key items missing in the responses was rendered unusable. 
A descriptive analysis was run to identify the respondents' characteristics. More than $58 \%$ of the respondents were in the range of 20 to 29 years old. A total of $26.5 \%$ of the sample were between 30 to 39 years old. This indicated a young sample. In terms of gender, the majority of the respondents were males (55.5\%) compared to females (44.5\%). On the average, the respondents indicated that they checked their e-mails at least five times per day. The majority of the respondents (56.1\%) subscribed to e-mail lists on websites that they visit to receive updates.

Subsequently, we ran a factor analysis (Table 1). This was to reduce a large number of variables to a smaller group of variables to make the analysis job easier (Pallant, 2007). The Principal Axis Factoring extraction method and the Varimax rotation method were used. A cut-off of 0.6 loading was used in consideration of the sample size. Those not meeting the criterion were subsequently omitted from further analysis. Following the factor analysis, reliability analysis and correlation analysis were conducted.

The paper began with the research question: What are the permissionbased e-mail factors from a recipient's perspective? In the following analyses, the paper provides the answer to this question.

The first four items labeled as FQ7_32, FQ8_33, FQ6_31, FQ3_28, FQ5_16, are grouped under Factor 1, since they relate to elements that recipients would forward an e-mail. Factor 1 is labeled as Forward. These items are summated into a scale (Hair et al., 2009) in SPSS and the result is saved under one scale called Forward to be used in subsequent analyses. This suggests users forward an e-mail that has attribute, landing page, copy, offer, and integration elements.

Factor 2 consists of items labeled as RQ5_16, OQ7_11, OQ6_10, RQ6_17, RQ7_18. These items make up the factor for a user to open and read an e-mail. The items are summated into a scale (Hair et al., 2009) in SPSS. Factor 2 is labeled as Open \& Read to be used in subsequent analyses.

Hypothesis 1 (H1) suggests that that a recipient with an intention to open an e-mail has the intention to read the e-mail. The result of Factor 2 groups open and read e-mail items together. This finding suggests support for Hypothesis 1. Further, this finding indicates that the e-mail recipient intends to open and read an e-mail that has integration, copy-writing and attribute factors. 
Items labeled as OQ2_6 and OQ7_5 make up Factor 3. These two items are also summated into a scale (Hair et al., 2009) in SPSS. Factor 3 is labeled as Open. This suggests users open an e-mail that has relevance to them and that contains creativity elements.

A total of three items labeled as CQ4_22, RQ4_15 and OQ4_8 are grouped under Factor 4 . The finding suggests that users open, read and click on a link inside an e-mail at a specific time of the day or week. The items are summated into one scale. Factor 4 is labeled as Open, Read \& Click to be used in subsequent analyses.

Factor 5 contains two items labeled as RQ3_14 and CQ3_21. These two items make up users' intention to open and click on a link in an e-mail. Factor 5 is designated as the Read $\mathcal{E}$ Click factor. The finding suggests that incentive relates to the recipients' intention to read and click on a link inside an e-mail.

Hypothesis $2(\mathrm{H} 2)$ suggests that a user with an intention to read an e-mail has the intention to click on a link in the e-mail. The outcomes of factor analysis through the emergence of Factor 4 and Factor 5 support Hypothesis 2. Notably, a user who intends to read an e-mail has the intention to click on a link in the e-mail at a specific time of the day or week and only when the e-mail contains an incentive for the user to do so.

Factor 6 and Factor 7 suggest the user's intention to click on a link inside an e-mail, therefore, Factor 6 is designated as Click1 and Factor 7 is called Click2. Click1 and Click2 suggest creativity and relevance elements.

Table 1

Factor Analysis

\begin{tabular}{|c|c|c|c|c|c|c|c|c|c|}
\hline \multirow[t]{2}{*}{ Code } & \multirow[t]{2}{*}{ Items } & \multirow{2}{*}{$\begin{array}{l}\text { Mean } \\
\text { score }\end{array}$} & \multicolumn{7}{|c|}{ Factor and Factor Loading } \\
\hline & & & 1 & 2 & 3 & 4 & 5 & 6 & 7 \\
\hline FQ7_32 & $\begin{array}{l}\text { I will forward an e-mail with } \\
\text { proper attributes (i.e. subject line, } \\
\text { date/time and header). }\end{array}$ & 2.92 & 0.747 & & & & & & \\
\hline FQ8_33 & $\begin{array}{l}\text { I will forward an e-mail that has a } \\
\text { link to an attractive Web page (also } \\
\text { known as landing page). }\end{array}$ & 2.94 & 0.723 & & & & & & \\
\hline
\end{tabular}

(continued) 
IJMS 22, Special Issue 1-19 (2015)

\begin{tabular}{|c|c|c|c|c|c|c|c|c|c|}
\hline \multirow[t]{2}{*}{ Code } & \multirow[t]{2}{*}{ Items } & \multirow{2}{*}{$\begin{array}{l}\text { Mean } \\
\text { score }\end{array}$} & \multicolumn{7}{|c|}{ Factor and Factor Loading } \\
\hline & & & 1 & 2 & 3 & 4 & 5 & 6 & 7 \\
\hline FQ6_31 & $\begin{array}{l}\text { I will forward an e-mail with } \\
\text { properly written phrase in the } \\
\text { content. (i.e. language use) }\end{array}$ & 2.92 & 0.722 & & & & & & \\
\hline FQ3_28 & $\begin{array}{l}\text { I will forward an e-mail that has an } \\
\text { attractive offer in it. }\end{array}$ & 3.03 & 0.615 & & & & & & \\
\hline FQ5_30 & $\begin{array}{l}\text { I will forward an e-mail that shows } \\
\text { integration between the sender's } \\
\text { name, subject line and contents. }\end{array}$ & 2.85 & 0.614 & & & & & & \\
\hline RQ5_16 & $\begin{array}{l}\text { I will read an e-mail that shows } \\
\text { integration between the sender's } \\
\text { name, subject line and contents. }\end{array}$ & 3.18 & & 0.655 & & & & & \\
\hline OQ7_11 & $\begin{array}{l}\text { I will open an e-mail with proper } \\
\text { attributes (i.e. containing subject } \\
\text { line, date/time and header). }\end{array}$ & 3.35 & & 0.651 & & & & & \\
\hline OQ6_10 & $\begin{array}{l}\text { I will open an e-mail with properly } \\
\text { written phrase in the subject line. } \\
\text { (i.e. language use) }\end{array}$ & 3.25 & & 0.650 & & & & & \\
\hline RQ6_17 & $\begin{array}{l}\text { I will read an e-mail with properly } \\
\text { written phrase in the contents. (i.e. } \\
\text { language use) }\end{array}$ & 3.16 & & 0.635 & & & & & \\
\hline RQ7-18 & $\begin{array}{l}\text { I will read an e-mail with proper } \\
\text { attributes (i.e. subject line, date/ } \\
\text { time and header). }\end{array}$ & 3.25 & & 0.608 & & & & & \\
\hline OQ2_6 & $\begin{array}{l}\text { I will open an e-mail that has a } \\
\text { subject line relevant to my needs. }\end{array}$ & 3.77 & & & 0.854 & & & & \\
\hline OQ1_5 & $\begin{array}{l}\text { I will open an e-mail that has an } \\
\text { attractive subject line. }\end{array}$ & 3.52 & & & 0.668 & & & & \\
\hline CQ4_22 & $\begin{array}{l}\text { I will click on a link in an e-mail at } \\
\text { a specific time of the day or day of } \\
\text { the week. }\end{array}$ & 2.52 & & & & 0.788 & & & \\
\hline RQ4_15 & $\begin{array}{l}\text { I will read an e-mail at a specific } \\
\text { time of the day or day of the week. }\end{array}$ & 2.58 & & & & 0.713 & & & \\
\hline OQ4_8 & $\begin{array}{l}\text { I will open an e-mail at a specific } \\
\text { time of the day or day of the week. }\end{array}$ & 2.77 & & & & 0.642 & & & \\
\hline RQ3_14 & $\begin{array}{l}\text { I will read an e-mail that has an } \\
\text { attractive offer in it. }\end{array}$ & 3.65 & & & & & 0.685 & & \\
\hline CQ3_21 & $\begin{array}{l}\text { I will click on a link in an e-mail } \\
\text { that has an attractive offer in it. }\end{array}$ & 3.41 & & & & & 0.651 & & \\
\hline CQ1_19 & $\begin{array}{l}\text { I will click on a link in an e-mail } \\
\text { that has an attractive design. }\end{array}$ & 3.24 & & & & & & 0.696 & \\
\hline CQ2_20 & $\begin{array}{l}\text { I will click on a link in an e-mail } \\
\text { that has contents relevant to my } \\
\text { needs. }\end{array}$ & 3.60 & & & & & & & 0.616 \\
\hline
\end{tabular}

Legend used - Factor 1: Forward, Factor 2: Open and Read, Factor 3: Open, Factor 4: Open , Read and Click, Factor 5: Read and Click, Factor 6: Click (Creativity), Factor 7: Click (Relevance) 
To measure the internal consistency or reliability, Cronbach's alpha coefficient is used. Cronbach's alpha coefficient should be more than 0.7 to ensure a reliable factor (Pallant, 2007). Table 2 shows the result of the reliability analysis for the entire data. Because Cronbach's alpha for all measures are greater than 0.7 , all factors in this research are deemed reliable.

Table 2

Reliability Analysis

\begin{tabular}{lcc}
\hline E-mail factors & No. of items & Cronbach's alpha \\
\hline Open & 2 & 0.75 \\
Forward & 5 & 0.86 \\
Open \& Read & 5 & 0.79 \\
Read \& Click & 2 & 0.70 \\
Open, Read \& Click & 3 & 0.76 \\
\hline
\end{tabular}

Consequently using correlation analysis (Table 3), we discuss the relationships among the permission-based e-mail factors. The correlation analysis results suggest that a recipient who frequently checks his e-mails, opens e-mails that are relevant to him and that are creative. Likewise, a recipient who checks his e-mail less frequently in a day may not necessarily open his e-mails.

Table 3

Correlation Analysis

\begin{tabular}{lcccccccc}
\hline $\begin{array}{l}\text { E-mail } \\
\text { Factor }\end{array}$ & $\begin{array}{c}\text { Times a } \\
\text { day }\end{array}$ & $\begin{array}{c}\text { Open } \\
\text { Open }\end{array}$ & $\begin{array}{c}\text { Open \& } \\
\text { Read }\end{array}$ & $\begin{array}{c}\text { Open, } \\
\text { Read } \\
\text { \& Click }\end{array}$ & $\begin{array}{c}\text { Read \& Forward Click1 } \\
\text { Click }\end{array}$ & Click 2 \\
Open \& Read & $0.184^{*}$ & 1 & & & & & & \\
Open, Read, Click & -0.088 & $0.167^{*}$ & 1 & & & & & \\
Read \& Click & 0.142 & 0.071 & 0.034 & 1 & & & & \\
Forward & 0.150 & $0.302^{* *}$ & $0.493^{* *}$ & $0.158^{*}$ & $0.271^{* *}$ & 1 & & \\
Click 1 & 0.07 & $0.286^{* *}$ & $0.342^{* *}$ & -0.013 & $0.408^{* *}$ & $0.366^{* *}$ & 1 & \\
Click 2 & 0.101 & $0.330^{* *}$ & $0.270^{* *}$ & 0.013 & $0.391^{* *}$ & $0.293^{* *}$ & $0.537^{* *}$ & 1 \\
\hline
\end{tabular}

Recipients who intend to open e-mails that they see as relevant and contain the creativity factor will also intend to open and read e-mails that show the integration, copy-writing and attribute factors. The recipients will read e-mails that have incentives and click on a link 
in these e-mails. Besides, they will click on e-mails that are creative and relevant to them. They will also forward the e-mails. Those who intend to open and read e-mails which show integration, copywriting and attribute factors will have the intention to forward these e-mails. Besides, they will click on the links in the e-mails that they see as relevant and creative. People who open, read and click on links in e-mails do that at a particular time of the day. They will read and click on the links that have incentives besides forwarding the e-mails to others.

Hypothesis $3(\mathrm{H} 3)$ suggests a user with the intention to read an e-mail has the intention to forward the e-mail. The results of the correlation analysis provide support for Hypothesis 3 that a user who intends to open an e-mail, also intends to read the e-mail. The user who intends to read the e-mail, in turn, intends to click on a link in the e-mail. Further, the user who intends to read the e-mail intends to forward the e-mail to others.

The time of the day plays a role in driving people to open, read and click on links in e-mails. Those who have the intention to engage in this behavior will forward e-mails that show integration, attribute, copy-writing, and landing page factors in them. Recipients who read and click on links in e-mails are driven by incentives in the e-mail. They will click on a link that has relevance to them and that they find creative. People will forward e-mails and click on links in the e-mails that they find relevant and creative. Relevant and creative e-mails are modestly related.

\section{Conclusion}

The paper has answered the research question and fulfills the aim of the research. The research has contributed to new knowledge about people's intention upon receiving permission-based e-mails. Intention is an important consideration as it has been shown to influence behavior (Fishbein \& Ajzen, 1975).

\section{Summary of Findings}

The findings provide empirical evidence to support all the hypotheses set out at the beginning of the research; notably does the e-mail recipient's intention to open an e-mail drive his intention to read the e-mail? This in turn forms the intention to click on a link in the e-mail. Finally, the recipient intends to forward the e-mail to others. 
One important consideration in the permission-based e-mail is to make an e-mail look relevant and creative to the recipients at first sight. This will drive the recipients to open their e-mails. This supports Liao et al. (2011). In a research on web portal they found creative matters relevant to users. The finding seems to suggest that if an e-mail does not live up to this expectation, the e-mail may just end up getting purposely deleted or remain in the spam box where it gets automatically removed. In other words, the first impression of an e-mail to recipients matters.

Users forward e-mails to others when e-mails have specific attributes and quality landing pages. This supports Karson and Fisher (2005) whose research on websites found that website attributes have direct relationship with user's intention to return to a particular website. The finding resonates well with Law and Bai (2007) who found evidence for the relationship between quality of landing pages and user's satisfaction.

When a recipient opens his e-mail, the expectation is that the e-mail is well-integrated in its contents and subject matter besides showing evidence that it has gone through copy-writing. This finding provides empirical evidence and supports earlier research made by Huang and Shyu (2009) that copy-writing relates to recipient's behavior and attention. The use of a proper language in an e-mail influences customers to feel more comfortable with the e-mail.

This research has found that incentive relates to recipients' intention to read and to click on a link inside an e-mail. This evidence is consistent with Rettie et al. (2002) and Amin et al. (2013) who found that permission-based e-mail with an attractive financial offer in it makes recipients perceive it as less intrusive.

Consequently, time factor matters to recipients as they open, read and click on a link at a specific time. Overall, the findings support Chaffey's (2003; 2007) e-mail factors and accordingly, this research has re-defined the Chaffey's (2003; 2007) model using the recipient's behavioral intention perspective.

\section{Implications for Theory}

This research has developed and tested a model that is built on Chaffey $(2003 ;$ 2007) and Fishbein \& Ajzen (1975). The model expands the original Chaffey CRITICAL e-mail factors by integrating an e-mail recipient's behavioral intention based on the downstream framework 
contributed by Fishbein \& Ajzen (1975). From a theoretical perspective, the research has contributed to new knowledge in explaining user's behavioral intention with regard to receiving permission-based e-mails. Further, the model has shown that a specific combination of factors in an e-mail is important in certain recipient's behavioral intention. In sum, the model can be used to explain both user's intention toward permission based e-mail behavior and specific e-mail factors that influence intention. Unlike Chaffey's original framework that focused on only each e-mail factor individually, this research has integrated all e-mail factors in explaining distinctly the recipient's behavioral intention with regard to permission-based e-mails. This sets the research distinct from other researches on permission-based e-mails.

\section{Implications for Practice}

The finding is vital for marketers in aiding them in the Electronic Age to design effective permission-based e-mails. Besides, the implication of the finding suggests a requirement for marketers to have integrated and multi-disciplinary knowledge that is typified in marketing, technology, communication and recipient's behavioral intention, and translating such knowledge into effective e-mail design.

The outcome of this research is important for marketers when designing e-mail campaigns. They may pay attention to these factors to ensure that the message gets across to not only the recipients but also to those connected to the recipients through various media and applications (apps) that include smartphones, tablets and e-mail apps. This has become crucial in the Electronic Age as people have become so easily connected via e-mails through their devices and apps. When an e-mail gets forwarded, marketers can maximize the benefits of campaigns and enhance the likelihood of the recipients and their connections to subscribe to their products or services. This suggests marketing educators at universities and institutions may benefit Internet retailers through provision of a structured program in permission-based e-mail strategies that integrates broad domain of knowledge of communication, marketing and technology.

\section{Limitations and Future Research}

Limitations exist in the research. The sample is drawn from one institution and at a point of time. Further, convenience sampling is used. Future research may consider cultural factors, other institutions or other countries and using probability sampling approach. 


\section{References}

Broekhuizen, T., \& Huizingh, E. K. R. E. (2009). Online purchase determinants: Is their effect moderated by direct experience. Management Research News, 32(5), 440-457.

Chang, H., Rizal, H., \& Amin, H. H. (2013). The determinants of consumer behavior towards e-mail advertisement. Internet Research, 23(3), 316-337.

Chaffey, D. (2007). E-business and E-commerce management: Strategy, implementation and practice (5th ed.). Essex: Pearson Education.

Chaffey, D. (2003). Total e-mail marketing. London: ButterworthHeinemann.

Fishbein, M., \& Ajzen, I. (1975). Belief, attitude, intention and behavior: An introduction to theory and research. New Jersey: AddisonWesley.

Forrester Research Annual Report. (2010). United States Securities and Exchange Commission, Washington, D.C. 20549.

Godin, S. (1999). Permission marketing: Turning strangers into friends, and friends into customers. New York: Simon and Schuster Publishing.

Grimes, G. A., Hough, M. G., \& Signorella, M. L. (2007). Email end users and spam: Relations of gender and age group to attitudes and actions. Computers in Human Behavior, 23, 318-332.

Ha, H., \& Im, Y. (2012). Role of website design quality in satisfaction and word of mouth generation. Journal of Service Management, 23(1), 79-96.

Hair, J. F., Black, W. C. Babin, B. J., \& Anderson, R. E. (2009). Multivariate data analysis. New Jersey: Prentice Hall.

Huang, J. H., \& Shyu, S. H. P. (2009). Building personalised relationships with customers via e-mails. Total Quality Management, 20(6), 585-601.

Jamalzadeh, M., Behravan, N., \& Masoudi, R. (2012). An empirical study of email-based advertisement and its influence on consumers' attitude. International Review of Management and Marketing, 2(3), 130-138.

Jolley, W., Lee, A., Mizerski, R., \& Sadeque, S. (2013). Permission email messages significantly increase gambler retention. Journal of Business Research, 66(9), 1617-1622.

Kabadayi, S., \& Gupta, R. (2011). Managing motives and design to influence web site revisits. Journal of Research in Interactive Marketing, 5(2/3), 153-169.

Kautonen, T., Jayawardhena, C., Kuckertz, A., Karjaluoto, H. (2009) Antecedents to permission-based mobile marketing: An initial examination. European Journal of Marketing, 3(4), 473-499. 
Krishnamurthy, S. (2001). A comprehensive analysis of permission marketing. Journal of Computer Mediated Communication, 6(2), $0-0$.

Law, R., \& Bai, B. (2007). How do the preferences of online buyers and browsers differ on the design and content of travel websites. International Journal of Contemporary Hospitality Management, 20(4), 388-400.

Liao, S., Shao, Y. P., Wang, H., \& Chen, A. (1999). The adoption of virtual banking: An empirical study. International Journal of Information Management, 19(1), 63-74.

Liao, C., To, P. L. Liu, C. C. , Kuo, P. Y., \& Chuang, S. H., (2011). Factors influencing the intended use of web portals. Online Information Review, 35(2), 237-254.

Lu, Y., Cao, Y., Wang, B., \& Yang, S. (2011). A study on factors that affect users' behavioral intention to transfer usage from the offline to the online channel. Computers in Human Behavior, 27(1), 355-364.

María-José Miquel-Romero, Consolacion Adame-Sánchez, (2013). Viral marketing through e-mail: The link company-consumer. Management Decision, 51(10), 1970-1982.

Martin, B. A. S., Van-Durme, J., Raulas, M., \& Merisavo, M. (2003). E-mail advertising: Exploratory insights from Finland. Journal of Advertising Research, 43, 293-300.

Merisavo, M., \& Raulas, M. (2004). The impact of e-mail marketing on brand loyalty. Journal of Product \& Brand Management, 13(7), 498-505.

Milne, G. R., \& Gordon , M. E. (1993). Direct mail privacy efficiency tradeoffs within an implied social contract framework. Journal of Public Policy and Marketing, 12(2), 206-215.

Mohamed, N., Hussein, R., Ahmad Zamzuri, N. H., \& Haghshenas, H. (2014). Individual's attributes, perception, experience, and online shopping continuance intention: Evidence from Malaysia. Industrial Management \& Data Systems, 119(4), 14531476.

Pallant, J. (2007). A step by step guide to data analysis using SPSS for windows version 15. Milton Keynes, UK: Open University Press.

Ramayah, T., \& Ignatius, J. (2005). Impact of perceived usefulness, perceived ease of use and perceived enjoyment on intention to shop online. IFCAI Journal of Management, 3(3), pp. 36-51.

Rettie, R., Grandcolas, U., \& Payne, V. (2002). E-mail marketing: Permission to pester. Retrieved from http://www.kingston. ac.uk/ ku03468/docs/permission.pdf 
Sterne, J., \& Priore, A. (2000). E-mail marketing: Using e-mail to reach your target audience and build customer relationships. New York: John Wiley \& Sons.

Teo, T. S. H. (2005). Usage and effectiveness of online marketing tools among business-to-consumer (B2C) firms in Singapore. International Journal of Information Management, 25(3), 203-213. 